\title{
How a single personal revelation might not be a source of knowledge
}

\author{
T. J. MAWSON \\ St Peter's College, Oxford, OX1 2DL
}

\begin{abstract}
Many of those who come to a belief in the God of classical theism do so solely as a result of having had an experience which they believe it is reasonable for them to interpret as a revelation of His existence directly and graciously given to them by God Himself. I shall argue that - at least in the first instance - such people should probably not think of themselves as knowing that there is a God if they are also traditional libertarians and believe in Robert Nozick's theory of knowledge.
\end{abstract}

\section{Introduction}

The speaker had made a lot of sense to me and as he got to the end of his talk I was surprised to find that I no longer thought that I knew that God did not exist. He hadn't convinced me that God did exist; he'd just persuaded me that I didn't know one way or the other. Then the speaker said that people who wanted to say a prayer asking God to come into their lives should go up to the front where there were helpers who would say the prayer with them. On a whim - thinking 'what have I got to lose?' - I went up to the front and said the prayer with someone there. No words can adequately describe what I experienced next, but I can say this: from that moment on I knew that there was a God. How? Because I'd met Him.

One frequently hears testimonies such as this at meetings designed to encourage more people to say prayers of the sort it describes. One assumption of those doing the encouraging at these meetings must be that one's freely choosing to say a prayer of this sort will make one more likely to receive an experience of this sort, a graciously given personal revelation. Another assumption may be that this experience will give one knowledge of the existence of God. Prima facie, it seems that, on any of the theistic religions, both of these assumptions are sound. If there is a God, then surely He is more likely to choose to reveal Himself in this way to someone who asks Him to do so than to someone who does not ask Him to do so; and if He does so reveal Himself, then surely at least some of these people 
can reasonably claim to know that He exists afterwards on the basis of their experiences.

This paper concerns only this second assumption, and it presents an argument to the effect that if it is sound, then either an influential understanding of the nature of free will is wrong or an influential understanding of the nature of knowledge is wrong. The influential understanding of the nature of free will in question is libertarianism, and the influential understanding of the nature of knowledge in question is that propounded by Robert Nozick, which I call the conditional theory. ${ }^{1}$ Amongst those who accept the argument of this paper, some will thus endorse libertarianism and the conditional theory of knowledge, arguing on this basis that faith so grounded and knowledge are mutually exclusive. I hazard that rather more will endorse libertarianism and accept that such experiences do provide one with knowledge, thus concluding that it is the conditional theory of knowledge that is false. And I expect that only a few will accept that such experiences provide one with knowledge and accept the conditional theory of knowledge, concluding that it is libertarianism that is false. To justify running the argument in one of these directions rather than the others would take several more papers and so, at the end of this one, having got the argument into running order, I leave it idling, ready for the reader to use to travel in whichever of these directions seems best to him or her.

\section{Nozick's theory}

Could one be in a position where all of the following were true? One believed a certain thing. One knew, and had an overall reasonable belief, that one had overall more/better reasons for believing that thing than not. One believed that thing because of these reasons. That thing was indeed true. And yet one's belief that it was true did not constitute knowledge. According to the conditional theory of knowledge, one could be in such a position.

Consider the following case. Ms A is considering whether or not she should believe that Mr B killed Ms C. Ms A has knowledge that B was alone in the room with $C$ when she was killed; that she had heard B shout, 'I'm going to kill you, C', moments before a single shot rang out; that nobody other than $\mathrm{B}$ had threatened to kill $\mathrm{C}$; that $\mathrm{C}$ was killed by a single gunshot; and that she had found $\mathrm{B}$ standing over C's body with a smoking gun in his hand a moment later. Given this, we would, I suggest, think that A has objectively good reasons for believing that $\mathrm{B}$ killed $\mathrm{C}$, and also incline to think that they are reasons which are good enough to mean that it is more reasonable for A to believe that B killed $\mathrm{C}$ than it would be for her to remain undecided, or to believe that B did not kill C. Let us suppose that A knows this and let us also suppose - what is not equivalent on the conditional theory of knowledge - that she has an overall reasonable belief in it too. Let us further suppose that A believes, in the light of these reasons, that B killed C. 
Her belief that B killed C is appropriately grounded on these facts; it is not grounded on some irrelevancy such as the fact that B's eyes are rather close together. Let us finally suppose that A is correct in believing that B killed C. He did kill her.

According to the conditional theory of knowledge, this is not sufficient to make it the case that A knows that B killed C. Whether or not A knows that B killed C depends not only on what actually happened, but also on what would have happened, had what actually happened failed to happen. We will be assisted in seeing the plausibility of the conditional theory if we give a more complete history of the world that A inhabits. What actually happened in A's world was this. B, intending to kill C, shouted, 'I'm going to kill you, C', whilst pulling out his gun with the purpose of doing so. Meanwhile, a certain Mr D, who also wanted C killed, simultaneously trained his silenced gun on $\mathrm{C}$ through the open window of the room from his position in the garden outside. Had B had second thoughts about shooting $\mathrm{C}$, then $\mathrm{D}$ would himself have shot her with his silenced gun. Had D shot $C$, then $B$, in frustration, would have fired a shot with his non-silenced gun out of the window after D's fleeing form. As it was, however, B shot and killed C, and so D ran away without firing his gun at all.

So it is that A lives in a world where, had B not killed C, then the evidence presented to her would have been the same: $\mathrm{B}$ would still have been the only person in the room with $\mathrm{C}$ when she was killed; A would still have heard B shout, 'I'm going to kill you, C', moments before a single shot rang out; $\mathrm{C}$ would still have been killed by a single gunshot; and $\mathrm{B}$ would still have been found by $\mathrm{A}$ standing over the body of $\mathrm{C}$ with a smoking gun in his hand a moment later. A would thus still have come to the belief that B had killed $\mathrm{C}$, basing her belief in B's guilt on the same good reasons. It is just that, had B not killed C, A's objectively reasonable belief that he had would have been false. As it is, however, $\mathrm{B}$ did kill C, and D ran off without firing a shot, so A's belief that B killed C is both objectively reasonable and true.

Given the facts concerning D, it is we might say 'just lucky' that A's belief that B killed $C$ is true. Were $B$ to have had second thoughts about shooting $C$, then $D$ would have shot $\mathrm{C}$, and thus A's belief that B had killed her would have been false. It is just 'luck' that B did not have second thoughts. According to the conditional theory of knowledge, luck playing this sort of role in the process leading to A's belief that B killed $\mathrm{C}$ is sufficient to make that belief-however objectively reasonable and true it actually is - not count as knowledge. The intuitive appeal of the conditional theory of knowledge lies in its thus separating the concept of objectively reasonable true belief from the concept of knowledge, so that if luck plays too big a role in the formation of one's belief on a particular occasion, then even if one has the former, one does not have the latter. Historically, it was an appreciation of the possibility that one might have objectively reasonable - or 'justified' - true belief, whilst not having knowledge, which paved the way for the 
conditional theory. ${ }^{2}$ Another attraction, at least for some, was that the conditional theory offers a solution to the problem of scepticism. However, it offers it at a price that many consider too high (the rejection of the principle of closure under known entailment). When there are other sellers in the epistemological marketplace - for example, content externalists and contextualists ${ }^{3}$ - who purport to offer, at a better price, something that will do the same job, it is these other sellers whose products attract most scrutiny; content externalism and contextualism currently generate more discussion than the conditional theory. Be that as it may, the conditional theory - arguably, in contrast to its competitors - is simple to state.

According to the conditional theory of knowledge, for one to know a certain proposition, $p$, one has to satisfy four conditions. Firstly, it has to be true that $p$. Secondly, one has to believe that $p$. Thirdly, it has to be true that if it had not been true that $p$, then one would not have believed that $p$. And fourthly, it has to be true that if, in slightly changed circumstances, it had still been true that $p$, then one would still have believed that $p$. The third and fourth conditions crystallize the requirement on knowledge that it - as we might say, following Nozick - 'tracks' the truth. For these conditions to be met, it is not sufficient that in the actual world one comes to a true belief that $p$. It has to be true that in the closest worlds in which $p$ is not true, one does not come to a belief that $p$ is true, and in the closest worlds in which $p$ is true, one comes to a belief that $p$ is true, which is all to say that the mechanism by which one actually comes to a true belief that $p$ cannot simply be a matter of luck. A's belief that B killed C does not satisfy the third condition for knowledge: if it had not been true that B had killed C, then A would still have believed that it was true. It is consequently too lucky to count as knowledge.

One objection to the argument of the previous paragraph would be that, whilst perhaps natural, it is rather arbitrary, when deciding whether or not A satisfies all the conditions laid down by the conditional theory of knowledge, to consider what would have happened had people chosen to behave differently, rather than to consider what would have happened had eventualities other than people's choices been different. There is a possible world in which $\mathrm{B}$ decides to kill $\mathrm{C}$ (as he does in the actual world), but then his gun jams; D then tries to kill C, but his gun jams too. This is a world in which it would not be true that B killed C, and yet it would be true that A did not believe that B killed C: she would presumably find B trying to un-jam his gun whilst standing beside an obviously alive, and probably rather nervous, $\mathrm{C}$ a few moments after having heard him issue his death threat. Why not think that this world is closer than the one where $\mathrm{B}$ decides at the last moment not to kill $\mathrm{C}$ ? We must be making an assumption that the closest worlds to any given world, at a given time, are those where a person or people chose differently at that time (or, if they are choosing from an atemporal eternity, in which their atemporal choice brings about its first temporal effect at that time). Such an assumption is questionable, but on libertarianism it is undeniable. 
Libertarianism requires one to believe that for a genuinely free choice to be made at time $t$ (or - if one is considering an atemporal choice - one the first temporal effect of which occurs at $t$ ), it has to be possible that the agent chose differently everything else in the universe remaining the same prior to $t$. On libertarianism, a different choice being made at $t$ or one the first temporal effect of which occurs at $t$ is then the smallest difference between worlds that there can be. On the traditional version of libertarianism - which has souls or God as the authors of such choices - it amounts to a simple indivisible substance having a different simple property. Two worlds cannot differ in any less respects than that. ${ }^{4} \mathrm{~A}$ world in which the guns of both B and D jammed would differ from the actual world in many respects: two (or more) complex substances (the guns) would each differ in several of their properties (or one very complex property jamming). Thus, on libertarianism, the closest possible world to a given world at time $t$ must be one that is identical save that a different choice is made at time $t$, or in which a different choice is made atemporally that brings about its first effect at $t$. So, at least on libertarianism and the conditional theory of knowledge, we should say that it is possible for one to have a belief that is true; that one knows (and has an overall reasonable belief) that one has overall objectively good reason to believe is true; that one believes because of these reasons; and yet that, nevertheless, does not constitute knowledge.

\section{The theory applied to the case of a single personal revelation}

Could one be in a position where all of the following were true? One believed that there is a God. One knew and was overall objectively reasonable in believing that one had more/better reasons for believing that there is a God than for believing that there is not. One believed that there is a God because of these reasons. There is indeed a God. And yet one's belief that there is a God did not constitute knowledge. We shall see that - on the conditional theory of knowledge and libertarianism - one could be in such a position, but for reasons which differ in interesting ways from those operative in our previous example.

Consider the following case. Ms A believes that there is a God of the sort that Jews, Christians, and Muslims worship, the God of classical theism and she is right - there is. She knows, and is overall objectively reasonable in believing, that up until time $t$ she had no more reasons in favour of the truth of classical theism than she had against it, and no more reasons against it than she had in favour of it. At that stage, she neither believed that there was a God, nor did she believe that there was not. She also knows, and is overall objectively reasonable in believing, the following. At time $t$ she uttered a prayer asking God, if He did exist, to speak to her. A moment after she had done so, a booming voice announced that He was God and talked to her for several hours about her life, displaying amazing wisdom and a knowledge of thoughts and feelings of A which she had never knowingly 
expressed to anyone else. A dozen or so other people witnessed the conversation, their testimonies concurring with one another and with A's recollections after the event. Tests indicated that there was no medical reason why A, or any of the other witnesses, would have had non-veridical experiences. Given this, we would, I suggest, say that A now has more objective reason to believe that God exists than not: in the light of the voice it would be objectively reasonable for A to believe that God existed, and it would be objectively unreasonable for her to continue undecided, or to believe that God did not exist. Let us suppose that A's belief that there is a God is based on her knowing, and having an overall objectively reasonable belief, that she has these reasons and that this is their status. It is not based on some irrelevant belief of hers such as that it would be rather nice if there were a God.

Is there then any way that A's belief that there is a God could not count as knowledge on the conditional theory and libertarianism? Paralleling our previous line of thought, we should ask what actually caused A's belief that there is a God, and what would have happened had this not happened: is A's reasonable belief only 'luckily' true? What caused A's belief was (her hearing) the voice, so we must ask what caused the voice. Let us consider some possibilities.

\section{World 1}

In World 1, what directly caused the voice was God, choosing to speak to her: ex nihilo, Humean-miraculously, He created sound waves which carried His voice to her and to the dozen or so witnesses in the vicinity. Had He not done so, A and these other people would have waited around for a few minutes and then gone off and done something else.

\section{World 2}

In World 2, what directly caused the voice was God, choosing to speak to her as in World 1. However, in contrast to World 1, had He not done so, then a $\mathrm{Mr}$ $\mathrm{B}$ - who was waiting nearby - would have used state-of-the-art technology to produce the same effect in A and the dozen or so other people nearby. B has been spying on A for several weeks and knows - from A's having talked in her sleep about A's deepest thoughts and feelings; these are the thoughts and feelings which she has never knowingly expressed to anyone else. B also, as it happens, has access to the world's most wise counsellors and, by pooling his own knowledge with the information they provide, he would thus be able to appear incredibly wise for the duration of the conversation with A. B is himself an atheist who has wagered with another atheist, Ms C, that with the technology and information at his disposal he can produce a false belief in A. The 'false' belief that $\mathrm{B}$ and $\mathrm{C}$ have agreed on is the belief that there is a God (a belief which of course each of them is actually ex hypothesi wrong in believing to be false). Wanting to win the bet, B has decided to act in this way. To his amazement, as he is just about 
to implement his plan, a voice which he cannot explain produces the effect which he was about to produce. This makes him change his mind, and he quietly packs up his equipment and goes home somewhat puzzled.

\section{World 3}

In World 3, B directly caused the voice. B is as he is in World 2, except that in this world he manages to execute his plan and 'win' his bet with C. God exists, but did not choose to speak directly to A. Nor would He have done so, even had B not acted as he did; in World 3 God had previously decided not to speak to A, whatever happened.

\section{World 4}

In World 4, B directly caused the voice. B is as he is in World 2, except that in this world, as in World 3, he manages to execute his plan. God exists, but did not choose to speak directly to A. However, in this world He was ready and willing to speak to A. God had previously decided that, were B not to act as he actually did, He Himself would Humean-miraculously intervene and directly produce the same effect. As it was, B did act and so God did not.

\section{Comparison}

A satisfies the first two conditions for knowledge of God's existence in all of these worlds; there is a God and she believes that there is. So, to see whether A knows that God exists in each or any of these worlds according to the conditional theory of knowledge and libertarianism, we must see in which of these worlds A satisfies the third condition for knowledge - that, had God not existed, she would not have believed that He did - and the fourth condition for knowledge - that had, in slightly changed circumstances, it still been the case that God existed, she would still have believed that He did.

In Worlds 3 and 4, A would have believed that God existed whether or not God had directly spoken to her (indeed in World 4 He does not speak to her) and thus we might be tempted to think that, in these worlds, her belief in His existence, grounded as it is in the experience of apparently hearing Him speak to her, cannot count as knowledge. Whilst it is true that, had God not spoken to her, A would still have believed that He existed, this does not make A's belief that God exists not count as knowledge by threatening the third condition. It does not do so for we are not considering whether or not A knows that God has spoken to her; we are considering whether or not she knows that He exists. Thus, to see if luck plays too much of a role for A's belief that God exists to count as knowledge, we must ask, not what would have been the case had He not spoken to her, but what would have been the case had He not existed. Once we realize that this should form our focus of concern with regard to whether or not A satisfies the third condition for knowing that God exists, we can see that A satisfies the third condition in all 
four worlds. In all four worlds it is true that, had God not existed, A would not have believed that He did, because in each of these worlds theism is correct. If theism is correct, then everything depends on God for its existence: had - per impossibile-God not existed, nothing would have existed; ipso facto, A would not have existed with a belief that He existed anyway. A's belief in God's existence satisfies the first three conditions in Worlds 1, 2, 3, and 4. We must therefore now ask whether it satisfies the fourth condition in all these worlds too.

The fourth condition on A's knowing that God exists requires it to be the case that had, in slightly changed circumstances, it still been the case that God existed, then A would still have believed that He existed. There are a number of circumstances one might consider changing but, given what was said previously, on libertarianism, we should consider first what would have happened had people chosen differently from the way they actually chose. In describing Worlds 1, 2, 3, and 4, we built into our descriptions how certain people would have behaved, had what actually happened not happened. Therefore, we cannot be left in any doubt about the features of what, on libertarianism, are the nearest worlds to Worlds 1, 2, 3, and 4 .

We said of World 1 that, had God chosen not to speak to A, then, as there was no $\mathrm{B}$ around to stand in and produce the voice, A would not have come to the belief that there was a God. Similarly, we said of World 3 that, had B chosen not to produce the voice (for example had he, at the last possible moment, decided that he ought not to deceive A - as he thinks of it - about so important a matter), then God would not have produced it either (for He had previously decided not to speak to A whatever happened), and thus A would not have come to the belief that there was a God. Thus, in Worlds 1 and 3, A fails to satisfy the fourth condition and therefore does not know there is a God, even though it is true that there is; she believes that there is; she knows herself to have (and has an overall objectively reasonable belief that she has) more objectively good reasons for believing that there is than for believing that there is not; and she believes that there is a God because of these reasons.

We said of World 2 that, had God chosen not to speak to A, then she would have believed that He existed because B would have intervened and produced phenomenologically the same effect; and of World 4 that, had B decided against producing these effects, then God would have produced them, again causing A to believe in Him. In Worlds 2 and 4, B and God have decided to behave this way, but then something happens (God speaking in World 2 and B in World 4) that stops them implementing their decision. Thus, in the closest worlds to 2 and 4 (where God does not speak for 2 and where B does not speak for 4), A still believes that there is a God. In Worlds 2 and 4, therefore, A satisfies the fourth condition and thus knows that there is a God; her reasonable true belief is also knowledge. This is obviously only on a fairly relaxed understanding of what is required for the fourth condition to be met. On more stringent understandings, where A would 
need to believe that there was a God in a larger range of close possible worlds for her belief in the actual world to count as knowledge, A would fail the fourth condition, and thus not count as knowing even in Worlds 2 and 4. We may say then that, on the conditional theory and libertarianism, in Worlds 1 and 3, A certainly does not know that there is a God; in Worlds 2 and 4 perhaps - even on these assumptions - she does.

We know that in our world there are not many situations in which there are people who are prepared to act like B. We know that we do not live in a world where it is generally the case that there are people who stand by prepared to induce the belief that there is a God in a particular person by producing experiences which will seem to that person as if God is speaking directly to them. We should assume that Worlds 1, 2, 3 and 4 are similar to ours save insofar as we have specified otherwise. On the assumption then that people who act in the manner of B are extremely rare in Worlds 1, 2, 3 and 4, it follows that, if A believes in the conditional theory of knowledge and libertarianism, then in each of these worlds she has most objective reason to think of her belief that there is a God as an objectively reasonable true belief which probably falls short of being knowledge by failing the fourth condition. ${ }^{5}$

\section{Conclusion}

If you are a traditional libertarian classical theist, who holds to the conditional theory of knowledge, and whose belief that there is a God is properly grounded solely on a religious experience, which you believe is contingent upon God's having freely chosen to communicate His existence to you - a graciously given personal revelation - then you should probably think that, if in slightly changed circumstances it had still been the case that God existed, you would not have believed that He did. You should believe that the world would not have had to have been in any way different, up until the moment of revelation, for Him to have chosen not to communicate His existence to you, and you should probably think that if He had not communicated His existence to you, you would not have believed that He existed. Thus, you should probably believe that in close possible worlds God exists, but you do not believe that He exists, and thus regard your actual belief that He does exist as failing the fourth condition for knowledge. You should probably believe this because it is improbable that you will have particular reason to think that there is someone, or something, that would have produced this belief even if God had not. You should believe that because God has freely chosen to reveal Himself to you, you are too lucky to count as a knower unless you have a particular reason to suppose that there is someone, or something, such as B around and, as in most cases you will not have a particular reason to suppose that there is someone or something such as B around, we may say that you should probably believe yourself too lucky to count as a knower. 
A similar argument may be made concerning our lack of knowledge of some of the mental states of other people. Consider the following situation. After dinner, John and Jane discuss whether or not one can know that there is a God solely as a result of a single experience of Him apparently speaking to one. Their discussion goes on into the early hours but, in the end, John calls a halt to it by saying, 'I'm sorry, I'm going to have to go to bed'. He gets up; they say their goodnights; and, as he is at the door, he says, 'I've actually been suffering from a slight headache for some time now. I've been debating with myself whether to bother mentioning it as it's so mild, but in the end I decided on a whim that I would. Do you happen to have anything I might take for it?' Jane replies that she has not and adds, 'You hide your pain very well; I'd never have suspected you had a headache'. 'Well, it's very mild', replies John, 'as I say, I almost chose not to mention it'. If each of them speaks truly, then in the closest possible world to the actual (or one of the closest possible worlds if the actual has quantum indeterminacy), John still has his headache, but Jane does not believe he has (because he chooses not to mention it). Thus, in the actual world, Jane has an objectively reasonable true belief that John has a headache, but it is one which does not constitute knowledge on the conditional theory of knowledge, as it fails the fourth condition. A large number of the mental states that we have reason to believe other people have, we only have reason to believe they have because they have chosen to reveal them to us; therefore, on the conditional theory of knowledge and libertarianism, our beliefs that they have these states do not constitute knowledge.

These are perhaps surprising results. It was perhaps surprising to learn that, on the conditional theory and libertarianism, A's status as a knower in World 2 depended on there being someone who stood by ready to try to deceive her, and in World 4 it depended on there being someone who actually did try to deceive her. It is perhaps surprising to learn that if one believes in God solely as a result of being overall objectively reasonable in interpreting a particular experience as a personal revelation, one should not regard one's belief that there is a God as knowledge (unless one believes that someone else would have produced the effect even if God had not), if one also subscribes to the conditional theory and libertarianism. It is perhaps surprising to learn that, on the conditional theory and libertarianism, one should not consider oneself to know of a large number of the mental states of others. When one reaches surprising results, proportional to one's surprise will be a tendency to run any valid argument leading to these results in reverse, using the results' 'obvious falsity' to cast doubt on one or more of the premises which led to them. We may therefore best conclude by stating the force of our argument as it applies to the epistemic status of a single divine self-revelation in two ways.

Given that one believes in the conditional theory of knowledge and libertarianism, one should not regard an experience of God graciously bestowed by 
God Himself as in itself a source of knowledge (unless one has reason to believe that one would have believed in God even if He had not chosen to communicate with one directly through that experience). Alternatively, given that one knows there is a God solely as a result of having had an experience of Him graciously bestowed by God Himself, and given that one knows that one would not have believed had He not graciously bestowed this gift on one, one should not believe in both the conditional theory of knowledge and libertarianism. ${ }^{6}$

\section{Notes}

1. Robert Nozick first described the conditional theory in his Philosophical Explanations (Cambridge, MA: Harvard University Press, 1981), $172 \mathrm{ff}$.

2. E. L. Gettier 'Is justified true belief knowledge?', Analysis, 23 (1963), 121-123.

3. Content externalism is of course associated most closely with the name of Hilary Putnam, as in Reason, Truth, and History (New York, NY: Cambridge University Press, 1981). 'Contextualism', as Ernest Sosa ('Skepticism and contextualism', Philosophical Issues, 10 (2000), Skepticism, 17), amongst others, has pointed out, is a somewhat elastic term. The term itself goes back at least to D. Annis's 'A contextualist theory of epistemic justification', American Philosophical Quarterly, 15 (1978), 213-219. But Stewart Cohen 'Knowledge, context and social standards', Synthese, 73 (1987), 3-26; Keith DeRose 'Solving the skeptical problem', Philosophical Perspectives, 2 (1988), 1-52; Michael Williams Unnatural Doubts: Epistemological Realism and the Basis of Scepticism (Oxford: Blackwell, 1992); and David Lewis 'Elusive knowledge', Australasian Journal of Philosophy, 74 (1996), 549-567 are all contextualists and yet all hold subtly different views. J. Tomberlin (ed.) Philosophical Perspectives, 13 (1999), Epistemology, 57 ff. contains useful papers on the varieties of contextualism.

4. A libertarian might admit that, if our world contains quantum indeterminacy, then another world $w^{*}$ could differ as minimally from our world $w$ as one where a different choice was made at $t$, without any person's choice being different at $t$ if (and only if) a fundamental particle, which went from having simple property $\mathrm{P}$ to having simple property $\mathrm{Q}$ in $w$ at $t$, went from having $\mathrm{P}$ to having simple property $\mathrm{R}$ in $w^{*}$ at $t$. However, it is implausible to suggest that such a microscopic physical change would in itself affect in any interesting way the macroscopic properties of $\mathrm{A}, \mathrm{B}, \mathrm{C}$ or D, which are the properties A has beliefs about.

5. In two of these worlds ( 2 and 4 ) this belief about her belief is, on the relaxed view, of course mistaken.

6. I am grateful to Peter Byrne, Richard Swinburne, and two anonymous referees of Religious Studies for their comments on earlier drafts of this paper. 